\title{
INFORME DE LA SOCIETAT VALENCIANA DE PSICOLOGIA AMB RELACIÓ AL DECRET DE PLURILINGÜISME DE LA GENERALITAT VALENCIANA
}

INFORME DE LA SOCIEDAD VALENCIANA DE PSICOLOGÍA EN RELACIÓN AL DECRETO DE PLURILINGÜISMO DE LA GENERALITAT VALENCIANA

REPORT FROM SOCIETAT VALENCIANA DE PSICOLOGIA RELATED TO GENERALITAT VALENCIANA'S MULTILINGUALISM DECREE

Societat Valenciana de Psicologia (SVP)

DOI: 10.7203/anuari.psicologia.18.1.199

Seguint la tradició d'aquesta Societat científica vinculada a la realitat socio-cultural valenciana, hem trobat oportú posicionar-nos amb relació al debat sobre els efectes i consequiències de l'aplicació del nou Decret de Plurilingüisme de la Generalitat Valenciana.

Cal recordar com, ja en el passat (1997), vam realitzar un informe a instàncies del Consell Valencià de Cultura, anomenat INFORME DE LA SOCIETAT VALENCIANA DE PSICOLOGIA SOBRE LA REALITAT PSICOLINGÜISTICA VALENCIANA, amb què contribuíem a un procés que donà com resultat la creació de l'Acadèmia Valenciana de la Llengua, institució amb la qual hem col-laborat habitualment en l'organització de jornades, fòrums i altres àmbits de debat.

Una d'aquestes jornades, concretament la VII Jornada-Debat del dia 12 d'abril de l'any 2016, es va realitzar a la Sala d'Actes de la Facultat de Psicologia, i va estar dedicada a la PSICOLOGIA I MULTILINGÜISME.

Ara, voldríem destacar algunes valoracions, derivades de la Psicologia del multilingüisme i els seus efectes:

1. L'entorn plurilingüe genera beneficis cognitius innegables. Proporciona major flexibilitat mental i major capacitat d'afrontament de problemes i resolució de conflictes, com ho demostren diverses investigacions.

2. La superació del model segregador de les antigues línies -valencià/castellà- presenta aspectes psicosocials molt positius. 
3. Considerem que el nou marc normatiu, que representa el Decret referit, obri oportunitats als xiquets i xiquetes escolaritzats i els prepara per a una realitat on la gestió de la diversitat i la tolerància ha de ser un valor essencial de convivència.

4. Dóna l'oportunitat que xiquets i xiquetes escolaritzats, d'àmbits geogràfiques i socioculturals de parla preferent en un idioma -per exemple zones castellanoparlants-, puguen, també, conéixer altres llengües -com és cas del valencià i l'anglés-, i garantir-ne així la seua no-discriminació futura -sociolaboral i d'altres- en zones lingüístiques on conviuen diverses llengües. Per tant, es produeix una millora als nivells competencials.

En definitiva, l'aplicació del Decret de Plurilingüisme genera un entorn educatiu en què els alumnes tenen contacte freqüent amb tres llengües. Això, en conjunt, genera més parlants multilingües, és a dir, capacitats per a expressar-se, amb diversos graus de fluïdesa, en tres idiomes. Des de l'òptica de la Psicologia, la capacitat de parlar diversos idiomes ha demostrat exercir un ampli ventall d'efectes beneficiosos sobre el funcionament cerebral (Bialystok i al., 2012). Entre els més coneguts, trobem l'augment de la facilitat per aprendre nous idiomes però també el retard en l'edat d'aparició de símptomes de malalties degeneratives (Chertkow i al., 2010). Més encara, al nivell estructural, la comparació entre bilingües i monolingües mostra que els primers tenen més densitat de substància grisa (Mechelli i al., 2004) i més connectivitat interneuronal (GarciaPenton i al., 2014), fets que proporcionen una sòlida base biològica per explicar els beneficis d'educar en el multilingüisme (Suay i Franco, 2015). Per tant, el sistema educatiu ha d'afavorir l'aprenentatge d'altres llengües, com és el cas del Decret que ens ocupa.

En la societat valenciana, majoritàriament, les famílies són o bé bilingües -tots dominen el castellà i el valencià-, o bé són monolingües -només dominen el castellà-. Actualment, amb la massiva presència del castellà en tots els nivell, no hi ha famílies valencianes que siguen monolingües en valencià. Això fa que els principals beneficiaris d'un sistema educatiu que promou el multilingüisme siguen les famílies de llengua castellana. Els seus fills serien els qui, en absència d'un sistema multilingüe, creixerien en ambients lingüísticament empobrits.

D'altra banda, el grau de bilingüisme que es pot promoure amb relació a l'anglés és diferent del que es produïx amb el castellà. En l'últim cas, tots els estudiants tenen ocasió d'utilitzar la llengua no sols en entorns acadèmics, sinó també en la vida quotidiana. Precisament això, l'experiència de l'idioma en diversos ambients socials, és un factor clau per a aproximar-se al bilingüisme real, i beneficiar-se dels efectes ja documentats. 
En definitiva, tot considerant l'estat actual de la societat valenciana, en què el castellà és la llengua dominant i d'ús majoritari, un sistema que prioritza l'ensenyament en valencià, i introduïx l'anglés, a més de mantenir el castellà com a llengua d'algunes assignatures, és l'únic que pot garantir l'assoliment de l'objectiu final: tenir competència en tres llengües.

Més encara, els beneficis del multilingüisme a mitjà i llarg termini semblen estar molt relacionats amb el grau de multilingüisme, i per als estudiants procedents d'entorns familiars monolingües constituïx un factor d'igualtat d'oportunitats, en la mesura que posa tots els estudiants en condicions similars de domini d'idiomes.

És el que manifestem a València a 10 d'abril del 2017.

\section{Referències}

Bhatia, T. K. i Ritchie, W. C. (2013). The Handbook of Bilingualism and Multilingualism, Chichester: Wiley-Blackwell.

Bialystok, E.; Fergus, I. M. Craik i Luk, G. (2012). Bilingualism: consequences for mind and brain. Trends in Cognitive Sciences, 16(4), pp. 240-250.

Chertkow, H.; Whitehead, V.; Phillips, N.; Wolfson, C.; Atherton J. i Bergman H. (2010). Multilingualism (but no talways bilingualism) delays the onset of Alzheimer disease: evidence from a bilingual community. Alzheimer Dis Assoc Disord, 24(2), pp. 118-125.

García-Pentón, L.; Pérez, F. A.; Iturria-Medina, Y.; Gillon-Dowens, M. i Carreiras, M. (2014). Anatomical connectivity changes in the bilingual brain. NeuroImage, 84, pp. 495-504.

Mechelli, A.; Crinion, J. T.; Noppeney, U.; O’Doherty, J. P.; Ashburner, J.; Frackowiak, R. S. i al. (2004). Structural plasticity in the bilingual brain: proficiency in a second language and age at acquisition affectgrey-matterdensity. Nature, 431(7010), p. 757.

Suay, F. i Franco, A. (2015). Impacte del bilingüisme sobre l'estructura cerebral. Llengua, Societat i Comunicació, 13, pp. 58-67.

Data de recepció: $\quad$ 12-04-2017

Data d'acceptació: 15-05-2017 